\title{
KAWASAKI DISEASE IN A PFAPA PATIENT: SHOULD BE AWARE OF THIS COMBINATION
}

\author{
Konstandinos DIAKOLIOS*, Evdoxia BOURAZANI, Alkistis ADRAMERINA, \\ Konstandina MACHAIRIDOU, Charalambos NEOCLEOUS
}

\author{
Department of Medical Pediatrics \\ General Hospital of Rhodes \\ Rhodes, Greece \\ *Corresponding author: \\ xneoc@yahoo.gr \\ Tel.: 00306955099935 \\ Fax.: 0035726271009
}

Received: June 17, 2015

Accepted: July 24, 2015

Key words: Kawasaki - PFAPA.

\begin{abstract}
Objective - In publishing this case we aim to support the primary association between Kawasaki Disease and periodic fever, aphthous stomatitis, pharyngitis and cervical adenitis syndrome (PFAPA) in children, a position that previously suggested by Ninomiya et al. (Development of Kawasaki disease in a patient with PFAPA. Pediatr Int. 2013; 55:801-2). Case report - A case of a 24-month-old boy with known PFAPA syndrome who developed Kawasaki disease is presented. Our case shared many similarities with the patient treated by Ninomiya et al. and supports their opinion that there might be a primary association between Kawasaki Disease and PFAPA syndrome in children. Conclusion - We suggest that there must be an awareness of this combination. Awareness of this association can lead the prompt diagnosis of Kawasaki disease and early treatment to reduce the sequelae.
\end{abstract}

\section{Introduction}

Kawasaki disease (KD) is an acute, self-limited vasculitis, affecting primarily mediumsized arteries, particularly the coronary arteries. It occurs predominantly in infants and young children and its aetiology remains unknown. Kawasaki disease is markedly more prevalent in Japan and in children of Japanese ancestry, with an annual incidence of $\approx 112$ cases per 100,000 children $<5$ years old. All deaths in patients with Kawasaki disease result from its cardiac sequelae. Coronary artery aneurysms or ectasia may develop in cases where children remain untreated. For this reason, KD is regarded as the most common cause of acquired heart disease in childhood in developed countries. The peak mortality occurs 15 to 45 days after the onset of fever; during this time well-established coronary vasculitis occurs (1-3). Periodic fever, aphthous stomatitis, pharyngitis and cervical adenitis syndrome (PFAPA) is one of the autoinflammatory diseases of unknown etiology characterized by regularly recurrent fever episodes (4).

We herein describe the second case of a PFAPA patient associated with the development of KD.

\section{Case report}

A 24-month-old boy was presented with a six-day history of fever and a two-day history of skin rash, red eyes and lips. A diagnosis of PFAPA syndrome had been established 12 months previously and the patient suffered from regularly recurring fever episodes. The symptoms during PFAPA attacks were typical and fulfilled the diagnostic criteria for this syndrome. The most recent fever attack due to PFAPA syndrome occurred two months prior to the patient's admission. The 
patient had not been given any medication for PFAPA. Physical examination in his present admission revealed bilateral conjunctival injection without discharge, fissured red lips, strawberry tongue, bilateral tender enlarged cervical lymph nodes and a nonspecific extensive diffuse maculopapular eruption with involvement of the trunk and extremities. His manifestation at the time of admission was inconsistent with that of PFAPA syndrome, as neither pharyngotonsillitis nor aphthous stomatitis was observed. The rest of the physical examination revealed no pathological findings. Laboratory results at admission, as well as those at follow-up are shown in Table 1.

\section{Table 1 Results of laboratory parameters}

\begin{tabular}{lll}
\hline Laboratory parameters & Day $1^{\text {st }}$ & Day $4^{\text {th }}$ \\
\hline White Blood Cells $\left(\times 10^{3} / \mu \mathrm{l}\right)$ & 19.20 & 13.21 \\
Neutrophils $(\%)$ & 34.8 & 32.3 \\
Lymphocyte $(\%)$ & 54.9 & 55.1 \\
Hemoglobin $(\mathrm{g} / \mathrm{dl})$ & 9.4 & 9.9 \\
Hematocrit $(\%)$ & 28.5 & 30.4 \\
Platelets $(\mathrm{per} / \mu \mathrm{l})$ & 797,000 & 935,000 \\
$\begin{array}{l}\text { Erythrocyte sedimentation rate } \\
(\mathrm{mm} / \mathrm{h})\end{array}$ & 70 & 71 \\
C-Reactive Protein $(\mathrm{mg} / \mathrm{dl})$ & 10.44 & 0.85 \\
\hline
\end{tabular}

The patient's clinical signs fulfilled the diagnostic criteria of $\mathrm{KD}(2)$ thus; a diagnosis of $\mathrm{KD}$ was established. Echocardiography revealed no pathological findings. On day one, $2 \mathrm{~g} / \mathrm{kg}$ i.v. immunoglobulin was given. The patient was apyrexial at the second day of hospitalization. Desquamation of hands and feet was observed two days after the fever subsided. The patient was discharged on day five without the need for further medical treatment at home. A follow-up echocardiography was recommended in 10 days and one and two months after hospital discharge. Written informed consent obtained from the parents of the patient for publication of this case report.

\section{Discussion}

Broderick et al. (5) suggested that patients with $\mathrm{KD}$ may have a genetic propensity toward altered immune response and autoinflammatory syndrome (PFAPA). On the other hand Ninomiya et al. (1) support the primary association between $\mathrm{KD}$ and PFAPA, as their patient, a two-year-old girl who suffered from PFAPA syndrome, had been diagnosed with $\mathrm{KD}$. The development of PFAPA was independent of the possible secondary dysregulation of innate immunity caused by KD. Ninomiya et al. (1) suggested that the association between $\mathrm{KD}$ and PFAPA may represent a genetic predisposition to dysregulated innate immune response. Our case shared many similarities with the case treated by Ninomiya et al. (1) and our report strengthens their opinion. On the other hand, it is worth noting that, similar to the case of Ninomiya et al. (1) it cannot be denied that $\mathrm{KD}$ may have occurred in our PFAPA patient by chance.

\section{Conclusion}

We strongly suggest that there must be an awareness of this combination. In this way prompt treatment can be initiated in a timely manner to reduce sequelae.

Authors' contributions: $\mathrm{CN}$ and $\mathrm{KD}$ had the original idea and along with $\mathrm{EB}$ wrote the paper. $\mathrm{KD}, \mathrm{CN}$, $\mathrm{EB}, \mathrm{AA}$ and $\mathrm{KM}$ collected the whole data, treated the patient and performed the follow-up assessment. $\mathrm{CN}$ and $\mathrm{KD}$ and $\mathrm{EB}$ wrote the final version of the paper. All authors have seen and approved the final version of the manuscript.

Conflict of interest: The authors declare that they have no conflict of interest.

\section{References}

1. Ninomiya T, Takada H, Nagatomo Y, Nanishi E, Nagata H, Yamamura K, et al. Development of 
Kawasaki disease in a patient with PFAPA. Pediatr Int. 2013;55(6):801-2.

2. Newburger JW, Takahashi M, Gerber MA, Gewitz MH, Tani LY, Burns JC, et al Committee on Rheumatic Fever, Endocarditis and Kawasaki Disease; Council on Cardiovascular Disease in the Young; American Heart Association; American Academy of Pediatrics. Diagnosis, treatment, and long-term management of Kawasaki disease: a statement for health professionals from the Committee on Rheumatic Fever, Endocarditis and Kawasaki Disease, Council on Cardiovascular Disease in the
Young, American Heart Association. Circulation. 200426;110(17):2747-71.

3. Eleftheriou D, Levin M, Shingadia D, Tulloh R, Klein NJ, Brogan PA. Management of Kawasaki disease. Arch Dis Child. 2014;99(1):74-83.

4. Feder HM, Salazar JC. A clinical review of 105 patients with PFAPA (a periodic fever syndrome). Acta Paediatr. 2010;99:178-84.

5. Broderick L, Tremoulet AH, Burns JC, Bastian JF, Hoffman HM. Recurrent fever syndromes in patients after recovery from Kawasaki syndrome. Pediatrics. 2011;127(2):e489-93. 